\title{
Modified Vaccinia Virus Ankara Antibody
}

National Cancer Institute

\section{Source}

National Cancer Institute. Modified Vaccinia Virus Ankara Antibody. NCI Thesaurus. Code C128468.

Any antibody that recognizes modified vaccinia Ankara virus. 